\title{
Differential in Vitro Suppressive Effects of Steroids on Leukocyte Phagocytosis in Two Teleosts, Tilapia and Common Carp
}

\author{
W an-Yu Law,* Wen-H siung C hen,* Yen-Lin Song, $†$ Sylive Dufour, $\ddagger$ \\ and $\mathbf{C}$ hing-Fong Chang $^{*, 1}$ \\ *D epartment of Aquaculture, N ational Taiwan 0 cean U niversity, Keelung 202, Taiwan, Republic of China; \\ †D epartment of Zoology, N ational Taiwan U niversity, Taipei 106, Taiwan, Republic of China; and łLaboratoire \\ de Physiologie, UM R 8572 CN RS, M useum National d'H istoire Naturelle, 75231 Paris Cedex 05, France
}

Accepted November 13, 2000

The objectives of this study were to investigate the potential roles of cortisol and gonadal steroids in the phagocytic activity of peripheral blood leukocytes in two teleosts, tilapia (Oreochromis niloticus $\times 0$. aureus) and common carp (Cyprinus carpio). An in vitro microtiter plate assay, measuring incorporation of FITC -latex beads into peripheral blood leukocytes, was developed for the first time in teleosts. Peripheral blood leukocytes were cultured in AL medium with tested compounds in a microfluor black plate at $25^{\circ} \mathrm{C}$. FITC -latex beads were further incubated for phagocytosis and engulfed fluorescent intensity in phagocytes was detected fluorometrically. Cortisol suppressed leukocyte phagocytosis in a dose $\left(10^{-14}\right.$ to $\left.10^{-4} \mathrm{M}\right)$ - and time $(0.5$ to $8 \mathrm{~h})$-dependent manner in tilapia. The glucocorticoid agonist dexamethasone had a suppressive effect similar to that of cortisol, while cortisone and the mineralocorticoid aldosterone had only a weak effect in tilapia. High doses of estradiol and ethynylestradiol, but not of estrone, suppressed phagocytosis in tilapia. No suppressive effect on phagocytosis was observed with various concentrations of progesterone, testosterone, and 11-ketotestosterone. Triiodothyronine was also inactive on phagocytosis. A combination of estradiol and cortisol potentiatingly suppressed phagocytosis. Actinomycin D and cycloheximide blocked the sup-

\footnotetext{
${ }^{1}$ To whom correspondence and reprint requests should be addressed. Fax: 886-2-2462-1579. E-mail: B0044@mail.ntou.edu.tw.
}

pressive effects of cortisol and estradiol. Cortisol had weaker suppressive effects on the phagocytosis of leukocytes in common carp than tilapia. Other steroids had no suppressive action on phagocytosis in common carp. It is concluded that the suppressive effects of cortisol and estradiol on phagocytosis in tilapia are mediated by specific glucocorticoid receptors and estrogen receptors, respectively. Cortisol would play a main and important role on the down-regulation of phagocytic activity. Sexual steroids, such as estradiol, also could interact with cortisol to further suppress immunity in tilapia. Differential responsiveness of the immune system to suppressive effects of steroids, among teleosts species, has been demonstrated. o 2001 Academic Press

Key W ords: fish; cortisol; estradiol; steroids; phagocytosis; leukocyte; tilapia; common carp.

\section{INTRODUCTION}

The interaction of the endocrine and immune systems is an important regulatory process in vertebrates. The development of the immune system and immunostimulation is likely to be dependent on growth hormone and prolactin in mammals (Blalock, 1994; Berczi, 1997; Clark, 1997) and fish (Calduch-Giner et al., 1995; Balm, 1997; Yada et al., 1999). Thyroid hor- 
mones stimulated phagocytosis activity in masu salmon, Oncorhynchus masou (Nagal et al., 1994). Suppression of the immune system by glucocorticoids has been shown in mammals (Goulding and Flower, 1997) and fish (Balm, 1997). Thus, the effects of growth hormone/prolactin and of glucocorticoids on immune and inflammatory reactions are antagonistic in nature. Stress via cortisol could inhibit the leukocyte function in the specific and/or nonspecific immunity ( $\mathrm{T}$ and $\mathrm{B}$ lymphocytes, natural killer cells, macrophages, and neutrophils) in mammals (Gouding and Flower, 1997). However, cortisol may also stimulate monocyte phagocytosis mediated by the $\beta$-glucan receptor in human (Kay and Czop, 1994) and increase phagocytosis of neutrophils in bovine milk (Fox and Heald, 1981). Cortisol effects on the immunity of fish include a decreased number of blood leukocytes and antibody in vivo in Atlantic salmon, Salmo salar (Ellis, 1981; Mazur and Iwama, 1993), a decreased number of lymphocytes and increased susceptibility to infection in brown trout, Salmo trutta in vivo (Pickering and Duston, 1983; Pickering, 1984), decreased phagocytosis in the macrophage of spleen and anterior kidney in rainbow trout, O. mykiss in vivo (Narnaware et al., 1994), inhibition of neutrophil apoptosis in common carp, Cyprinus carpio in vitro (Weyts et al., 1998), decreased numbers and mitogenic activities of blood lymphocytes but increased neutrophils in channel catfish, Ictalurus punctatus in vitro (Ellsaesser and Clem, 1987), and a reduced mitogenic activity of blood lymphocytes in Atlantic salmon, S. salar, in vitro (Espelid et al., 1996). Dexamethasone but not cortisol significantly depressed macrophage phagocytosis in vitro in the anterior kidney and spleen of rainbow trout, O. mykiss (Narnaware et al., 1994). Cortisol even could have permissive, suppressive, or stimulatory actions in various animals (Sapolsky et al., 2000).

There are few consistent data on the effects of sex steroids on the immune system (Grossman, 1985; Balm, 1997). The phagocytosis of leukocytes was increased but the numbers of blood lymphocyte and monocytes were reduced by estradiol treatment in the sow (Magnusson and Einarsson, 1990). Estradiol inhibited cell-mediated immunity and phagocytosis in porcine leukocytes (Magnusson, 1991; Josefsson et al., 1992). Estradiol also suppressed phagocytosis in the macrophage cell line of goldfish (Wang and Belosevic, 1995). Testosterone inhibited macrophage phagocyto- sis in chicken (Al-Afaleq and Homeida, 1998) and killed leukocytes in the anterior kidney of chinook salmon, O. tshawaytscha (Slater and Schreck, 1997). Progesterone but not estradiol significantly reduced neutrophil function in steers (Roth et al., 1982) and suppressed cell-mediated immunity in hamster (Kincl and Ciaccio, 1980).

Phagocytosis is an important process in the nonspecific immune system. Macrophages and neutrophils are the main cells responsible for phagocytosis. Leukocytes collected from anterior kidney or spleen are often used for the in vitro study of phagocytosis (Narnaware et al., 1994; Narnaware and Baker, 1996; Calduch-Giner et al., 1997; Narnaware et al., 1997; Mondal and Rai, 1999). The circulatory system contains large numbers of phagocytic cells, such as hemocytes in invertebrates and macrophages/neutrophils in vertebrates, and they have been used to obtain reproducible, quantitative, and nonsubjective phagocytosis data via a microtiter plate assay. This system provides a valuable tool for further investigating the interaction between the endocrine and immune systems. The present objectives were to investigate the potential roles of cortisol and gonadal steroids on the phagocytosis activity of peripheral blood leukocytes in a microtiter plate assay in two teleost species, tilapia and common carp.

\section{MATERIALS AND METHODS}

\section{Fish}

Male tilapia (Oreochromis niloticus $\times$ O. aureus, average body weight $920 \pm 161 \mathrm{~g}$, body length $54 \pm 8$ $\mathrm{cm}$ ) and common carp (C. carpio, average body weight $575 \pm 100 \mathrm{~g}$, body length $33.0 \pm 1.5 \mathrm{~cm}$ ) were purchased from the fish market. The fish were kept in a freshwater system for more than 1 month before study.

\section{Preparation of Peripheral Blood Leukocytes}

Fish were anesthesized in $0.02 \%$ benzocane solution (Sigma; St. Louis, MO) and blood was collected from the caudal vasculature of fish with heparin (Sigma). The preparation of blood leukocytes was modified 
from the methods of Miller et al. (1994). Blood was mixed with AL medium (AIM-V medium and Leibovitz's L 15 medium w/l -glutamine, w/o $\mathrm{NaHCO}_{3}$, GIBCO, 1/1, v/v) (1/3, v/v) and streptomycin and gentamicine. Lymphoprep (density, 1.077, Nycomed Pharma As, Norway) (4/3, v/v) was added to mixed blood solution and then it was centrifuged at $350 \mathrm{~g}$ for $20 \mathrm{~min}\left(10^{\circ} \mathrm{C}\right)$. The leukocytes were obtained from the interface and washed with AL medium. After centrifugation $\left(600 \mathrm{~g}\right.$ for $\left.10 \mathrm{~min}, 10^{\circ} \mathrm{C}\right)$, the leukocytes were suspended in AL medium containing $5.5 \mathrm{mM}$ glucose. The viability and number of leukocytes were counted by adding trypan blue with a hematocytometer.

\section{The Analysis of Leukocyte Phagocytosis by a Microtiter Plate Assay}

The methods were modified from the procedures of Anderson and Mora (1995). About $1.5 \times 10^{5}$ leukocytes in $50 \mu \mathrm{l}$ AL medium with glucose were added in a microfluor black plate (Nunc-Immuno Modules, Roskilde, Denmark) in the presence or the absence of test compounds, and it was then incubated for several hours ( $4 \mathrm{~h}$ in tilapia, $8 \mathrm{~h}$ in common carp) at $25^{\circ} \mathrm{C}$ in air. After incubation at $25^{\circ} \mathrm{C}, 50 \mu \mathrm{l}$ of FITC-latex beads (0.105 $\mu \mathrm{m}$, Sigma) in $0.02 \mathrm{M}$ phosphate-buffered saline solution ( $\mathrm{pH} 7.0$, Sigma) and $50 \mu \mathrm{l}$ of trypan blue quenching buffer (trypan blue in citrate buffer, $\mathrm{pH} 4.5$, Sigma) were added and incubated at $25^{\circ} \mathrm{C}$. The fluorescence remaining in the cultured medium was blocked by the trypan blue quenching buffer. The fluorescent intensity of the engulfed cells was measured by a MFX Microtiter Plate Fluorometer (Dynex, U.S.A.). The phagocytosis index was $100 \%$ in the control and the relative phagocytosis index in the treated group was calculated. The tested compounds (Sigma) were as follows: cortisol, cortisone, aldosterone, dexamethasone, testosterone, 11-ketotestosterone, progesterone, estradiol, estrone, ethynylestradiol, and triiodothyronine. Actinomycin D and cycloheximide (Sigma) were also used to test the blocking of the suppressive effects of steroids.

To obtain optimal experimental conditions, experimental conditions such as different ratios of latex beads per leukocyte $\left(2,3,4,5\right.$, and $6 \times 10^{4}$ beads /cell), the incubation time (from 5 to $180 \mathrm{~min}$ ) of FITC-latex beads and leukocytes, and the quenching time (from 2 to $30 \mathrm{~min}$ ) of trypan blue quenching buffer in the mixture of latex beads/leukocytes were assessed, respectively. The optimal condition for the experiment was as follows: $5 \times 10^{4}$ latex beads/leukocyte, $40 \mathrm{~min}$ incubation between latex beads and leukocytes, and 10 min quenching with a trypan blue quenching buffer.

\section{Statistical Analysis}

One-way analysis of variance followed by Duncan's multiple range test was conducted to test the significant difference $(P<0.05)$ (Steel and Torrie, 1980). Results are given as a mean \pm standard error of the mean (SEM).

\section{RESULTS}

\section{Phagocytosis in Tilapia: D ose and Time Dependency of the Suppressive Effect of C ortisol}

Tilapia macrophage-engulfed FITC-latex beads appeared fluorescent green under fluorescent field microscopy (Fig. 1). Leukocyte viability, before and after the treatment with a tested compound, was more than $95 \%$ and not different. Various final concentrations $(0$, $0.01 \mathrm{pM}, 1 \mathrm{pM}, 0.1 \mathrm{nM}, 10 \mathrm{nM}, 1 \mu \mathrm{M}$, and $0.1 \mathrm{mM})$ of cortisol were incubated with tilapia leukocytes for 0.5 , $1,2,4,6$, and $8 \mathrm{~h}$, respectively. The dose-dependent response and time course of the phagocytosis effects of cortisol are shown in the Fig. 2. Incubations for as little as $2 \mathrm{~h}$ with a high dose of $1 \mu \mathrm{M}$ cortisol or for $8 \mathrm{~h}$ with a low dose of $1 \mathrm{pM}$ cortisol could significantly suppress phagocytosis. The maximal suppression of phagocytic activity ( $40 \%$ phagocytosis index) was observed with cortisol at $0.1 \mathrm{mM}$ for $8 \mathrm{~h}$ incubation.

\section{Comparative Effects of Various C orticosteroids on Phagocytosis in Tilapia}

Four hours of incubation between tested chemicals and leukocytes was selected to investigate the phagocytic index in the presence of the various compounds. Both cortisol and the glucocorticoid agonist dexamethasone had a significant effect on the suppression of phagocytosis (Fig. 3). Dexamethasone is slightly more active than cortisol. Similar values and maximal ef- 

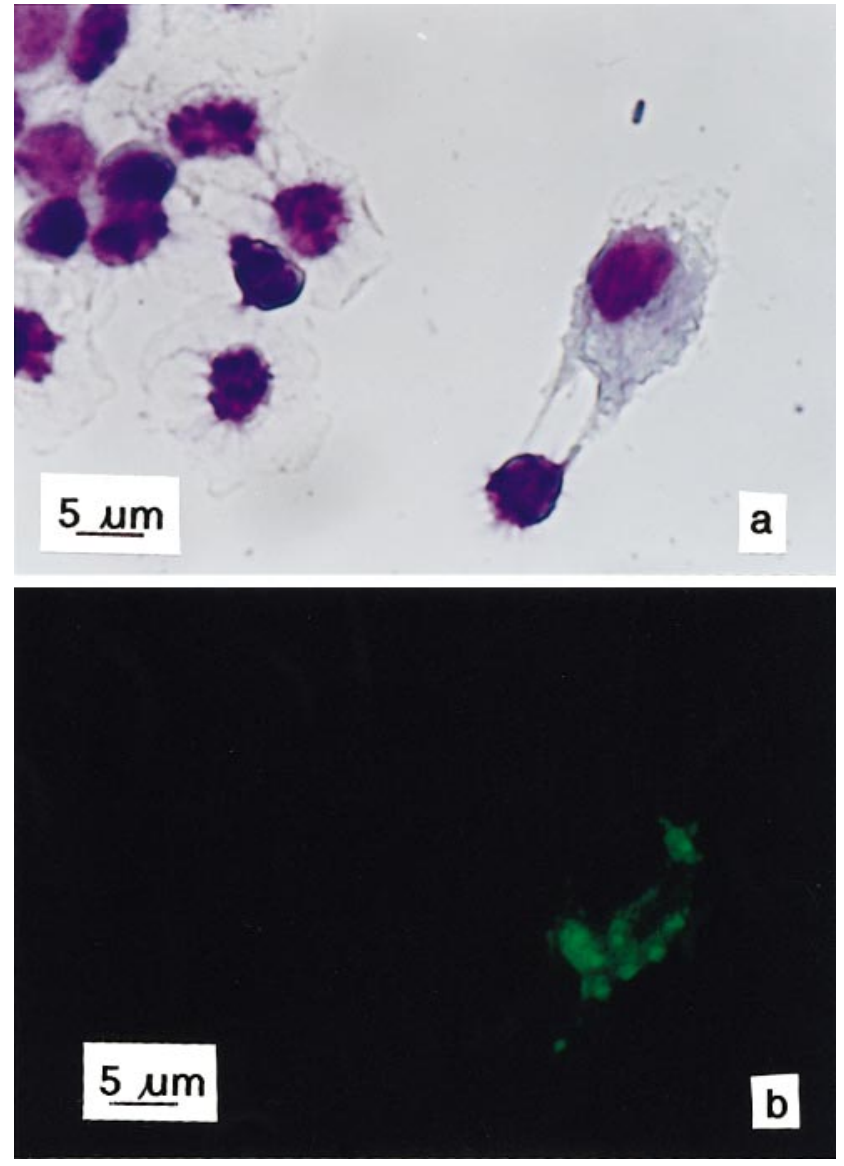

FIG. 1. Giesma stain of tilapia attached peripheral blood leukocytes (PBL). PBL were observed with bright-field (a) and fluorescent-field (b) microscopes. A macrophage engulfing FITC-latex beads was shown with green color for fluorescence.

fects were observed in $1 \mu \mathrm{M}$ and $0.1 \mathrm{mM}$ dexamethasone and $0.1 \mathrm{mM}$ cortisol (Fig. 3). Cortisone and a mineralocorticoid, aldosterone, had very weak effects.

\section{Comparative Effects of Various Sex Steroids and Thyroid Hormone on Phagocytosis in Tilapia}

High doses (10 nM, $1 \mu \mathrm{m}$, and $0.1 \mathrm{mM}$ ) of estradiol and ethynylestradiol but not estrone significantly inhibited phagocytosis (Fig. 4a). All three compounds at a $10 \mathrm{nM}$ dose, cortisol, estradiol and ethynylestradiol, started to show suppressive phagocytic activity (Figs. 3 and $4 \mathrm{a}$ ). The phagocytic indices were 60,82 , and $80 \%$ in treatments with $0.1 \mathrm{mM}$ cortisol, estradiol, and ethynylestradiol, respectively (Fig. 4a). The maximal suppressive action on phagocytosis of estrogenic com-

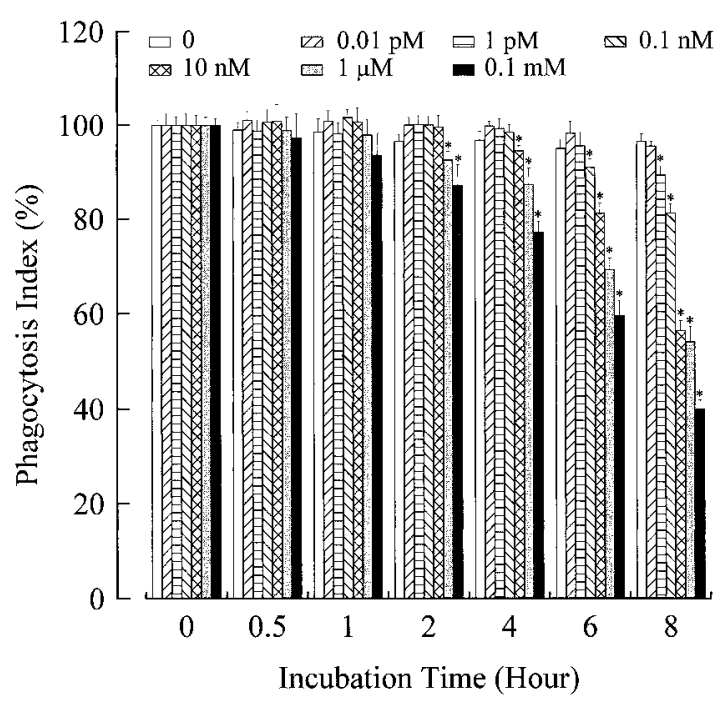

FIG. 2. The effects of cortisol $(0-0.1 \mathrm{mM})$ and incubation time $(0-8$ h) on the phagocytosis index (\%) in tilapia leukocytes. Values represent means \pm SEM. An asterisk indicates a significant difference $(P<0.05)$ from the respective control (without cortisol treatment).

pounds was detected at $1 \mu \mathrm{M}$ and $0.1 \mathrm{mM}$ ethynylestradiol (Fig. 4a). In contrast, there was no significant effect on phagocytosis with various concentrations of other gonadal steroids, progesterone, testosterone, and 11-ketotestosterone, nor of thyroid hormone, triiodothyronine (Fig. 4b).

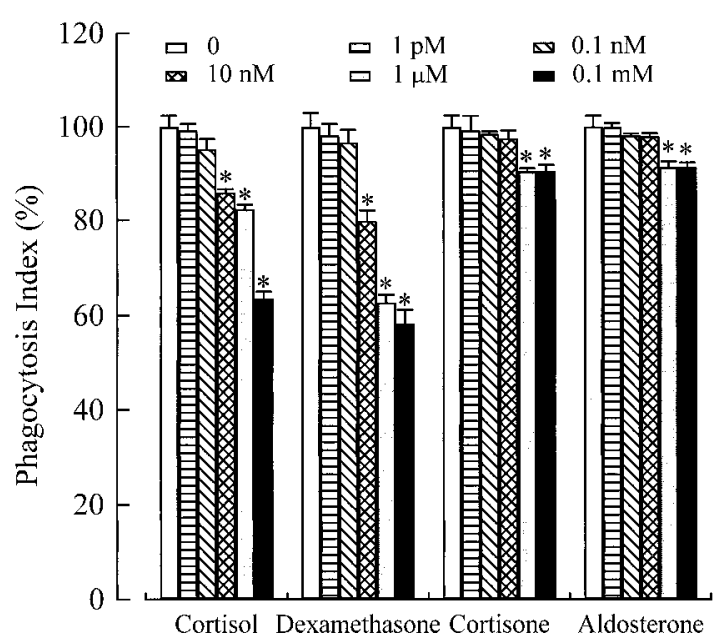

FIG. 3. The effects of cortisol, dexamethasone, cortisone, and aldosterone (0-0.1 $\mathrm{mM}$ for each chemical) on the phagocytosis index $(\%)$ in tilapia leukocytes. Values represent means \pm SEM. An asterisk indicates a significant difference $(P<0.05)$ from the respective control (without steroid or analog treatment). 

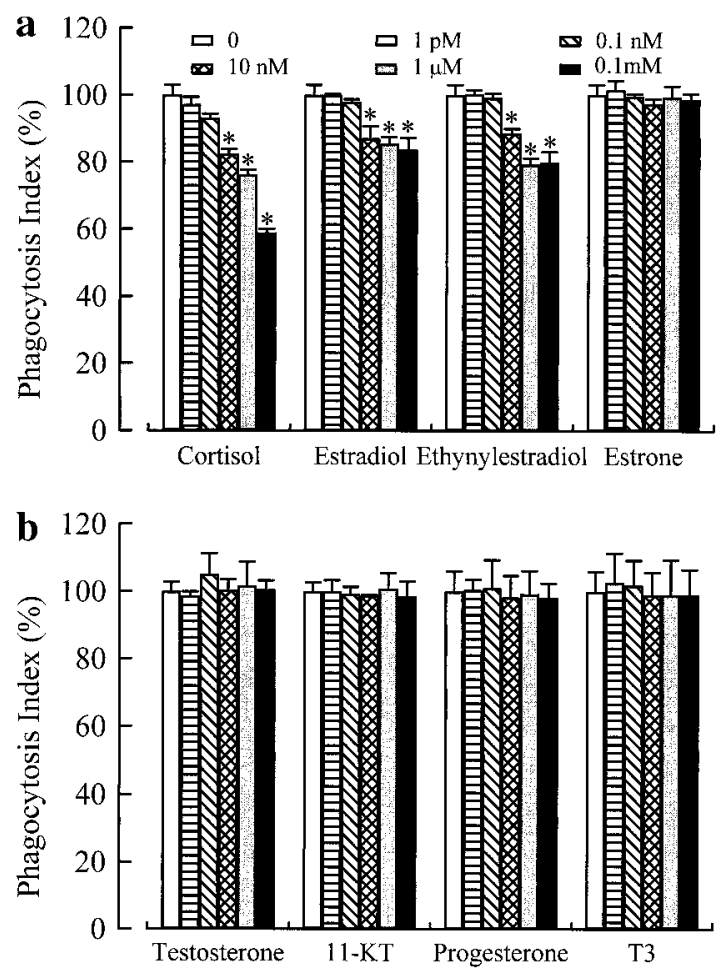

FIG . 4. The effects of sexual steroids and thyroid hormone (0-0.1 $\mathrm{mM}$ for each hormone) on the phagocytosis index (\%) in tilapia leukocytes; (a) cortisol, estradiol, ethynylestradiol, and estrone; (b) testosterone, 11-ketotestosterone (11-KT), progesterone, and triiodothyronine $\left(T_{3}\right)$. Values represent means \pm SEM. An asterisk indicates a significant difference $(P<0.05)$ from the respective control (without hormone or analog treatment).

\section{Effects of Combined Treatments with C ortisol and Estradiol on Phagocytosis in Tilapia}

The effects of combinations of different concentrations of estradiol and cortisol are shown in Fig. 5a. In the presence of an inactive dose of estradiol $(0.1 \mathrm{nM})$, which is inactive alone, the suppressive action of cortisol on phagocytosis was enhanced. The maximal inhibitory effect corresponding to $60 \%$ is at a cortisol concentration of $1 \mu \mathrm{M}$ instead of $0.1 \mathrm{mM}$ (Fig. 5a). Furthermore, in the presence of a low dose of estradiol $(10 \mathrm{nM})$, the effective dose of cortisol was significantly reduced (10 $\mathrm{nM}$ vs $1 \mathrm{pM})$, and its maximal inhibitory effect was enhanced (up to $40 \%$ versus $60 \%$ of the phagocytosis index) (Fig. 5a). In comparison, no further suppression of phagocytosis was observed when testosterone was added to different concentrations of cortisol (Fig. 5b).

\section{Effects of Actinomycin D and Cycloheximide on Cortisol or Estradiol Suppression of Phagocytosis in Tilapia}

Whether the suppressive effects of cortisol and estradiol could be reduced by inhibitors of transcription and translation was investigated. As shown in Fig. 6, actinomycin D and cycloheximide blocked the suppressive effects of cortisol and estradiol in a dosedependent manner (Fig. 6).

\section{Leukocyte Phagocytosis in Common Carp: D ose and Time Dependence of the Suppressive Effect of Cortisol}

Only high doses of cortisol ( $1 \mu \mathrm{M}$ or $0.1 \mathrm{mM})$ over a long incubation period (6 or $8 \mathrm{~h}$ ) significantly inhibited leukocyte phagocytosis in common carp (Fig. 7). Comparison with tilapia showed that leukocyte
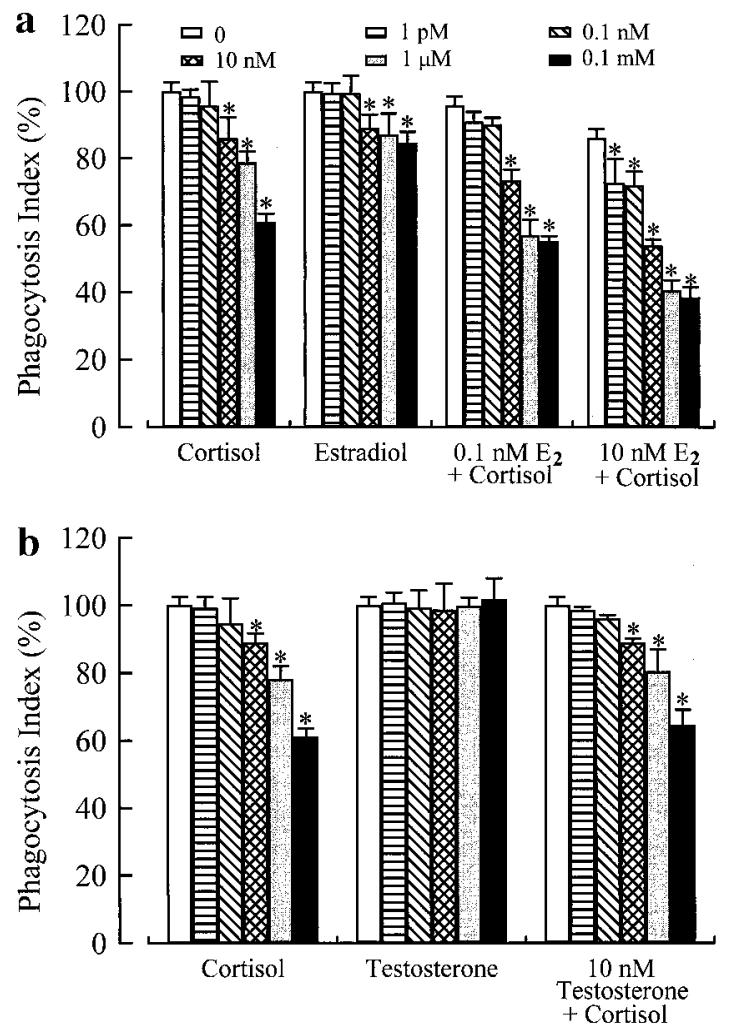

FIG. 5. Interaction of cortisol $(0-0.1 \mathrm{mM})$ with (a) estradiol $\left(\mathrm{E}_{2}\right)$ $(0.1$ and $10 \mathrm{nM})$ and (b) testosterone $(10 \mathrm{nM})$ on the phagocytosis index $(\%)$ in tilapia leukocytes. Values represent means \pm SEM. An asterisk indicates a significant difference $(P<0.05)$ from the respective control (without steroid treatment). 


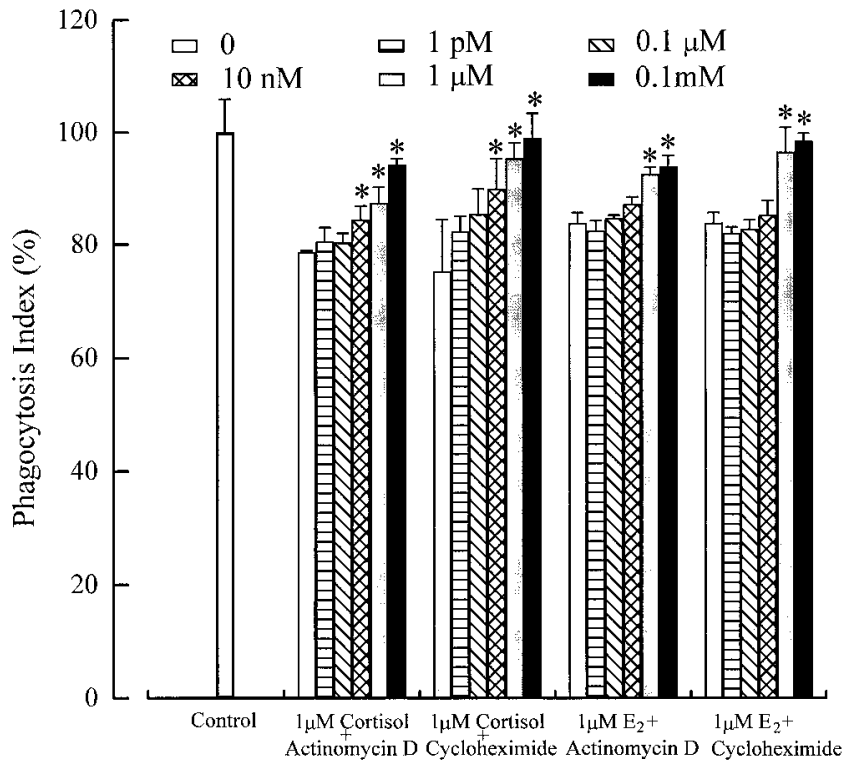

FIG. 6. Actinomycin $\mathrm{D}(0-0.1 \mathrm{mM})$ and cycloheximide $(0-0.1$ $\mathrm{mM})$ inhibited cortisol $(1 \mu \mathrm{M})$ and estradiol $(1 \mu \mathrm{M})$ effects on phagocytosis in tilapia leukocytes. Values represent means \pm SEM. An asterisk indicates a significant difference $(P<0.05)$ from the respective control (without inhibitor treatment).

phagocytosis in common carp was much less sensitive to cortisol inhibition (Fig. 8). Therefore, further study of leukocyte phagocytosis in common carp was conducted for $8 \mathrm{~h}$ incubation.

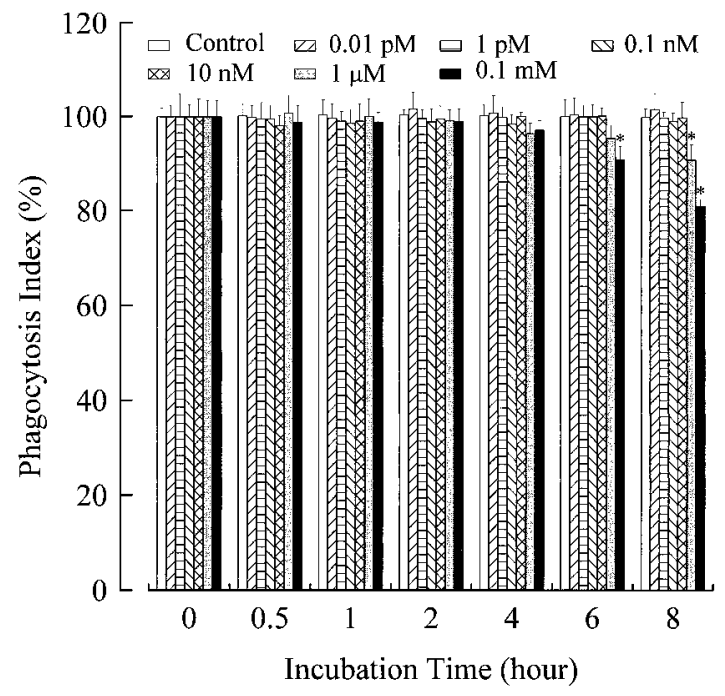

FIG . 7. The effects of cortisol $(0-0.1 \mathrm{mM})$ and incubation time $(0-8 \mathrm{~h})$ on the phagocytosis index (\%) in common carp leukocytes. Values represent means \pm SEM. An asterisk indicates a significant difference $(P<0.05)$ from the respective control (without cortisol treatment).

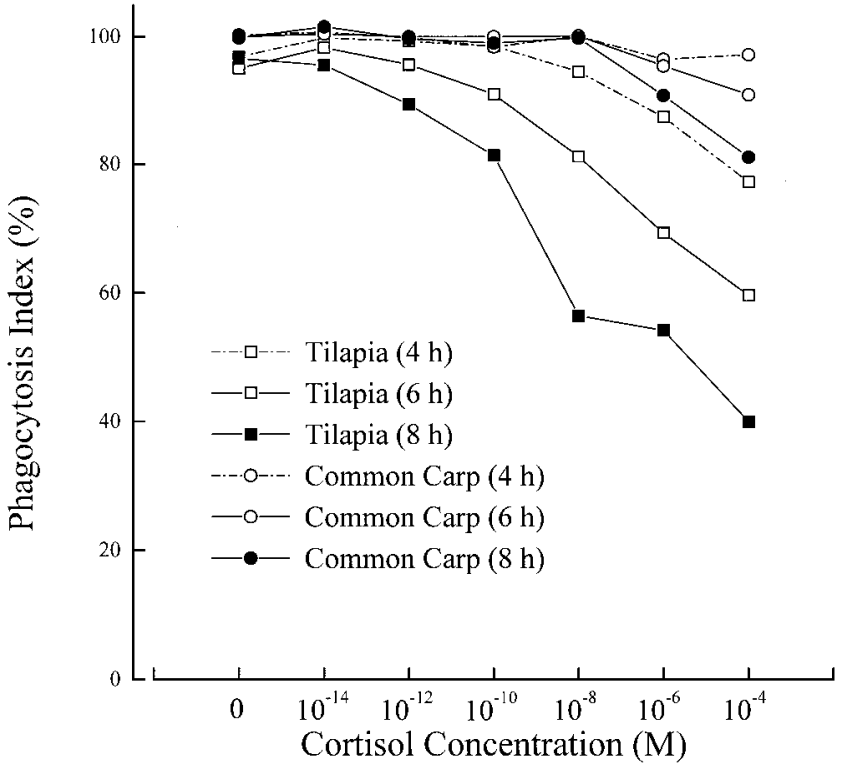

FIG. 8. Comparison of cortisol (0-0.1 mM) effects on the phagocytosis index (\%) of leukocytes in tilapia and common carp. Incubation times of leukocytes and cortisol were 4,6 , and $8 \mathrm{~h}$, respectively.

\section{Lack of G onadal Steroid Effect on Phagocytosis in Common Carp}

There were no inhibitory actions of various doses (1 pm, $0.01 \mathrm{nM}, 10 \mathrm{nM}, 1 \mu \mathrm{M}$, and $0.1 \mathrm{mM}$ ) of estradiol, testosterone, and 11-ketotestosterone on leukocyte phagocytosis (Fig. 9a). Estradiol also had no additive effects on the cortisol-inducing inhibition of phagocytosis (Fig. 9b).

\section{DISC USSION}

Phagocytes have a major role in the cellular immune responses of fish, especially in fighting against bacteria. The factors that are involved in fish for the regulation of phagocytosis remain to be established. Peripheral blood provides a more consistent and easily handled source for the collection of leukocytes compared to the anterior kidney or spleen. The detected sensitivity, repeatability, and easy handling of engulfed fluorescent intensity in the whole well by the fluorescent photometer in the present experiment was much better than observations from microscopy (in- 

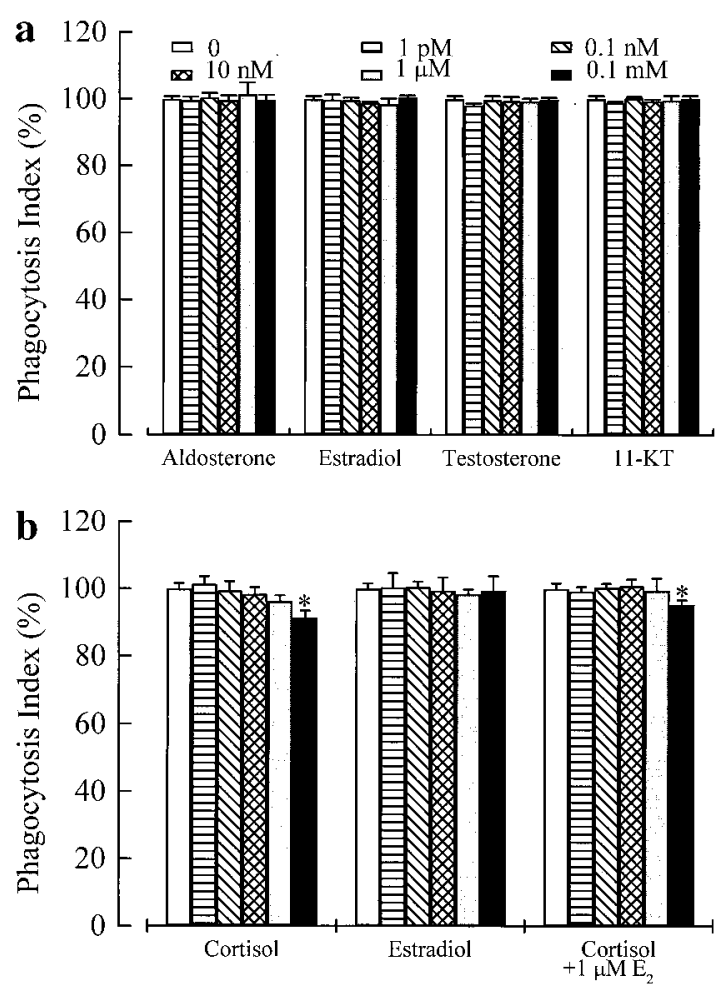

FIG. 9. The effects of (a) estradiol, testosterone, and 11-ketotestosterone (11-KT) $(0-0.1 \mathrm{mM}$ each steroid) and (b) interaction of cortisol $(0-0.1 \mathrm{mM})$ and estradiol $\left(\mathrm{E}_{2}, 1 \mu \mathrm{M}\right)$ on the phagocytosis index $(\%)$ in common carp leukocytes. Values represent means \pm SEM. An asterisk indicates a significant difference $(P<0.05)$ from the respective control (without steroid treatment).

specting 200 leukocytes for calculation of the phagocytosis index) (Narnaware et al., 1994, 1997). The FITClatex beads are also better than yeast (Narnaware $e t$ al., 1994; Narnaware and Baker, 1996) or sheep red blood cells (Carlson et al., 1993; Calduch-Giner et al., 1997) because of ease of handling, preserving, and selecting of smaller particle sizes. After evaluating the ratio of latex beads per leukocyte, incubation time of latex beads and leukocytes, and quenching time, it is considered that peripheral blood leukocytes could provide a valuable tool for the first time in teleosts to study phagocytosis in a microtiter plate assay with FITC-latex beads.

The present data demonstrated that cortisol significantly inhibited leukocyte phagocytosis in tilapia, as in some other fish and other vertebrates. The inhibition depends on dosage and incubation time. Plasma cortisol levels are significantly elevated and could be $10^{-7} \mathrm{M}$ when animals are exposed to stressful environ- ments and the elevated levels could last for several hours to days (Strange et al., 1977; Leach and Taylor, 1980; Sun et al., 1994). Therefore, cortisol levels in leukocyte phagocytosis experiment in the present study were from physiological $\left(10^{-8}\right.$ to $\left.10^{-7} \mathrm{M}\right)$ to pharmacological $\left(10^{-6}\right.$ and $\left.10^{-4} \mathrm{M}\right)$ doses. Inhibitory effects on phagocytosis were consistently observed at various doses of cortisol in this experiment. Cortisol also reduced phagocyte ability to generate a chemiluminescence response in striped bass when exposed to bacteria or phorbol esters (Stave and Robertson, 1985). A suppressive effect of cortisol on lipopolysaccharide mitogenesis was demonstrated in peripheral blood cells from Atlantic salmon in vitro (Espelid et al., 1996). In contrast, cortisol at a low dose enhances phagocytosis in human (Kay and Czop, 1994) and bovine (Fox and Heald, 1981). No effect of cortisol on phagocytosis was found in anterior kidney and spleen of rainbow trout (Narnaware et al., 1994). In the present study, the responsiveness of leukocytes from two different teleost species, tilapia and common carp, were compared by using the same experimental conditions. Tilapia was much more susceptible to cortisol effects than the common carp. There are clearly species differences in the regulation of leukocyte phagocytosis in fish.

There are a few studies of gonadal steroid effects of nonspecific immunity in animals. In the present studies, estradiol and the estradiol pharmacological agonist ethynylestradiol significantly suppressed leukocyte phagocytosis in tilapia but only at higher doses $\left(10^{-8}, 10^{-6}\right.$, and $\left.10^{-4} \mathrm{M}\right)$. The amplitude of the suppressive effects was lower with estradiol than with cortisol. Other gonadal steroids, such as androgens (testosterone, 11-ketotestosterone) and progesterone, had no significant effects, indicating the estrogen specificity of the suppressive effects in tilapia.

In contrast to the suppressive effect of estradiol on phagocytosis in tilapia, gonadal steroids had no effects in common carp under similar experimental conditions. Inhibition by estradiol of nonspecific immunity occurs in some mammals, such as sow and porcine, but not in steers (Magnusson, 1991; Josefsson et al., 1992). Testosterone can also suppress nonspecific immunity in chicken (Al-Afaleq and Homeida, 1998). Dihydrotestosterone strongly, but estradiol only weakly, inhibited splenic macrophage phagocytosis in wall lizards (Mondal and Rai, 1999). In teleosts, estra- 
diol inhibits nonspecific immunity in goldfish (Wang and Belosevic, 1995). Five or more days of incubation with testosterone was required to elicit significant in vitro immunosuppression in anterior kidney leukocytes in chinook salmon (Slater and Schreck, 1997). Testosterone and cortisol administered in vitro together had a significantly greater inhibitory effect on antibody-producing cells than did either administered alone in chinook salmon (Slater and Schreck, 1993). It is apparent that gonadal steroid effects on nonspecific immunity vary according to the type of steroid and the species of teleost.

In the present study, cortisol and estradiol had a potentiating effect on the suppression of phagocytosis in tilapia. High estradiol levels are found in female fish, especially during oocyte development (vitellogenesis) (Fostier et al., 1983). The data might suggest that reproduction (increased sex steroids) and stress (increased cortisol) might have a profound interaction on immunity in fish during the spawning season, as also indicated in brown trout, S. trutta (Pickering, 1984). This might explain the different resistance to disease infection between female and male fish and also seasonal effects. (Slater and Schreck, 1993). The present results, which showed no effect on leukocyte phagocytosis of the main steroid produced in male fish (aromatizable androgen, such as testosterone, nor nonaromatizable androgen, such as 11-ketotestosterone) may account for the lower susceptibility of males than females to disease infection in some species. The strong inhibitory effect on phagocytosis of the combination of cortisol and estradiol, as demonstrated in this study, may provide an endocrine bases for the high susceptibility to disease infection and the change of immune function at certain reproductive stages and/or in gender in human and animals (Roth et al., 1983; Schuurs and Verheul, 1990; Grossman et al., 1991; Mondal and Rai, 1999). It is male fish that appear to be more susceptible to disease during sexual maturation in rainbow trout (Sumpter et al., 1987). Reduction in the magnitude of the cortisol level in plasma to stress was observed in the mature male compared with immature rainbow trout (Pottinger et al., 1995). Sexual dimorphism in the phagocytic activity of the wall lizard's splenic macrophages was detected because of sex steroid effects of dihydrotestosterone in males (Mondal and Rai, 1999). The interaction between sex steroids and cortisol in the induction of immunosuppression should be further studied in vivo and in vitro in more species.

The present data also suggest that specific glucocorticoid receptors and estrogen receptors are responsible for the involvement of cortisol and estradiol actions in tilapia. Glucocorticoid receptors have been identified in the anterior kidney leukocytes in coho salmon (Maule and Schreck, 1990). Further identification of glucocorticoid receptors and estrogen receptors in the peripheral blood leukocytes of tilapia is needed. Stimulation of gene expression and protein synthesis may mediate the action of cortisol and estradiol on leukocyte phagocytosis because actinomycin D and cycloheximide could block inhibitory actions. It has been shown that cortisol stimulated the production of a new protein $(\mathrm{I} \kappa \mathrm{B} \alpha)$, and $\mathrm{I} \kappa \mathrm{B} \alpha$ hold NF- $\kappa \mathrm{B}$ in an inactive form to prevent the synthesis of cytokines (mediators for immune system) (Marx, 1995; McKay and Cidlowski, 1999). It is possible that the pathway of estradiol action is similar to that of cortisol (McKay and Cidlowski, 1999). However, not all the ligands that bound to the nuclear receptors would automatically suppress phagocytosis because testosterone, 11ketotestosterone, progesterone, and triiodothyronine did not have any effect in tilapia. Another consideration is whether specific receptors for these steroids are present in tilapia leukocytes.

It is also interesting that the common carp is much more resistant to the inhibitory effects of steroids on phagocytosis than tilapia. There is about a $10^{5}$ - to $10^{6}$-fold difference between tilapia and common carp in terms of cortisol concentrations to suppress a similar degree of phagocytosis. Estradiol also did not have any effects on phagocytosis in common carp. The data may suggest that the common carp is more resistant than tilapia when exposed to environmental stressors (low temperatures) or disease infections (Sun et al., 1994; Chen et al., 1995). It is still unclear whether cyprinids in general are less sensitive to cortisol than other groups of fish (such as tilapia).

The affinity of glucocorticoid receptors is in the nanomolar range in the liver $\left(K_{d}\right.$ of $\left.\sim 0.5 \mathrm{nM}\right)$ of rainbow trout, O. mykiss (Pottinger, 1990), leukocytes $\left(K_{d}\right.$ of $\sim 1.0 \mathrm{~nm}$ ) of coho salmon, O. kisutch (Maule and Schreck, 1990), and peripheral blood leukocytes $\left(K_{d}\right.$ of $3.8 \mathrm{nM}$ ) of common carp (Weyts et al., 1998). Tilapia peripheral leukocytes were very sensitive to cortisol concentrations as low as $1 \mathrm{pM}$ (after $8 \mathrm{~h}$ incubation) in 
the present experiment. The detected binding affinity of receptors may not truly reflect the cortisol levels in physiological action. The binding affinity of the glucocorticoid receptor is apparently not different in fish. However, the present data demonstrated that carp leukocytes are less sensitive to steroids than are those of tilapia. The rationale for these differences between carp and tilapia is not clear. The binding sites of glucocorticoid receptors could be down-regulated by high levels of cortisol or stressors in rainbow trout (Pottinger, 1990). Any difference in the basal and stressed levels of plasma cortisol in tilapia and common carp may contribute to the different sensitivity to steroids of these two species. Further investigation also could address the question of whether the differential effects of steroids on phagocytosis between tilapia and common carp are associated with differential expression of specific steroid receptors in leukocytes.

\section{ACKNOWLEDGMENT}

This work was supported in part by the National Science Council in Taiwan (NSC 87-2311-B019-004-B28, NSC 88-2311-B019-001-B28).

\section{REFERENCES}

Al-Afaleq, A. I., and Homeida, A. M. (1998). Effects of low doses of estradiol, testosterone and dihydrotestosterone on the immune response of broiler chicks. Immunopharmacol. Immunotoxicol. 20, 315-327.

Anderson, R. S., and Mora, L. M. (1995). Phagocytosis: A microtiter plate assay. In "Techniques in Fish Immunology, Vol. 4: Immunology and Pathology of Aquatic Invertebrates" (J. S. Stolen, T. C. Fletcher, S. A. Smith, J. T. Zelikoff, S. L. Kaattari, R. S. Anderser, K. Soderhall, and B. A. Weeks-Perkins, Eds.), pp. 109-112. SOS, Fair Haven, NJ.

Balm, P. H. M. (1997). Immune-endocrine interactions. In "Fish Stress and Health in Aquaculture" (G. K. Iwama, A. D. Pickering, and C. B. Schreck, Eds.), pp. 195-221. Cambridge Univ. Press, Cambridge.

Berczi, I. (1997). Prolactin, growth hormone and host defence. In "Stress, Stress Hormones and the Immune System" (J. C. Buckingham, G. E. Gillies, and A. M. Cowell, Eds.), pp. 337-356. Wiley, New York.

Blalock, J. E. (1994). The syntax of immune-neuroendocrine communication. Immunol. Today 15, 504-511.
Calduch-Giner, J. A., Sitja-Bobadilla, A., Alvarez-Pellitero, P., and Perez-Sanchez, J. (1995). Evidence for a direct action of GH on haemopoietic cells of a marine fish, the gilthead sea bream (Sparus aurata). J. Endocrinol. 146, 459-467.

Calduch-Giner, J. A., Sitjà-Bobadilla, A., Alvarez-Pellitero, P., and Pèrez-Sànchez, J. (1997). Growth hormone as an in vitro phagocyte-activating factor in the gilthead sea bream (Sparus aurata). Cell Tissue Res. 287, 535-540.

Carlson, R. E., Anderson, D. P., and Bodammer, J. E. (1993). In vivo cortisol administration suppresses the in vitro primary immune response of winter flounder lymphocytes. Fish Shellfish Immunol. 3, 299-312.

Chen, G. R., Sun, L. T., Lee, Y. H., and Chang, C. F. (1995). Characteristics of blood in common carp, Cyprius carpio, exposed to low temperature. J. Appl. Aquacult. 5, 21-31.

Clark, R. (1997). The somatogenic hormone and insulin-like growth factor-I: Stimulators of lymphopoiesis and immune function. Endocr. Rev. 18, 157-179.

Ellis, A. E. (1981). Stress and the modulation of defense mechanisms in fish. In "Stress and Fish" (A. D. Pickering, Ed.), pp. 147-169. Academic Press, London.

Ellsaesser, C. F., and Clem, L. W. (1987). Cortisol-induced hematologic and immunologic changes in channel catfish (Ictalurus punctatus). Comp. Biochem. Physiol. 87A, 405-408.

Espelid, S., Løkken, G. B., Steiro, K., and Bøgwald, J. (1996). Effects of cortisol and stress on the immune system in Atlantic salmon (Salmo salar L.). Fish Shellfish Immunol. 6, 95-110.

Fostier, A., Jalabert, B., Billard, R., Breton, B., and Zohar, Y. (1983). The gonadal steroids. In "Fish Physiology" (W. S. Hoar, D. J. Randall, and E. M. Donaldson, Eds.), Vol. IX, pp. 277-372. Academic Press, New York.

Fox, L. K., and Heald, C. W. (1981). Effect of cortisol on the bactericidal function of the bovine milk neutrophil in vitro. Am. J. Vet. Res. 42, 1933-1936.

Goulding, N. J., and Flower, R. J. (1997). Glucocorticoids and the immune system. In "Stress, Stress Hormones and the Immune System" (J. C. Buckingham, G. E. Gillies, and A. M. Cowell, Eds.), pp. 337-356. Wiley, New York.

Grossman, C. J. (1985). Interactions between the gonadal steroids and the immune system. Science 227, 257.

Grossman, C. J., Roselle, G. A., and Mendenhall, C. L. (1991). Sex steroid regulation of autoimmunity. J. Steroid Biochem. Mol. Biol. 40, 646-659.

Josefsson, E., Tarkowski, A., and Carlsten, H. (1992). Antinflammatory properties of estrogen I. In vitro suppression of leukocyte production in bone marrow and redistribution of peripheral blood neutrophils. Cell. Immunol. 142, 67-78.

Kay, J., and Czop, J. K. (1994). Enhancement of human monocyte beta-glucan receptors by glucocorticoids. Immunology 811, 96-102.

Kincl, F. A., and Ciaccio, L. A. (1980). Suppression of immune responses by progesterone. Endocrinol. Exp. 14, 27-33.

Le Morvan, C., Clerton, P., Deschaux, P., and Troutaud, D. (1997). Effects of environmental temperature on macrophage activities in carp. Fish Shellfish Immunol. 7, 209-212. 
Leach, G. J., and Taylor, M. H. (1980). The role of cortisol in stressinduced metabolic changes in Fundulus heteroclitus. Gen. Comp. Endocrinol. 42, 219-227.

Magnusson, U. (1991). In vitro effects of prepartum concentrations of oestradiol-17 $\beta$ on cell-mediated immunity and phagocytosis by porcine leukocytes. Vet. Immunol. Immunopathol. 28, 117-126.

Magnusson, U., and Einarsson, S. (1990). Effects of exogenous oestradiol on the number and functional capacity of circulating mononuclear and polymorphonuclear leukocytes in the sow. Vet. Immunol. Immunopathol. 25, 235-247.

Marx, J. (1995). How the glucocorticoid suppress immunity. Science 270, 232-233.

Maule, A. G., and Schreck, C. B. (1990). Glucocorticoid receptors in leukocytes and gill of juvenile coho salmon (Oncorhynchus kisutch). Gen. Comp. Endocrinol. 77, 448-455.

Mazur, C. F., and Iwama, G. K. (1993). Handling and crowding stress reduces number of plaque-forming cells in Atlantic salmon. J. Aquatic Anim. Health 5, 98-101.

McKay, L. I., and Cidlowski, J. A. (1999). Molecular control of immune/inflammatory responses: Interactions between nuclear factor- $\kappa \mathrm{B}$ and steroid receptor-signaling pathways. Endocr. Rev. 20, 435-459.

Miller, N. W., Chinchar, V. G., and Clem, L. W. (1994). Development of leukocyte cell lines from the channel catfish (Ictalurus punctatus). J. Tissue Cult. Methods 16, 117-123.

Mondal, S., and Rai, U. (1999). Sexual dimorphism in phagocytic activity of wall lizard's splenic macrophages and its control by sex steroids. Gen. Comp. Endocrinol. 116, 291-298.

Nagal, M., Fuda, H., Jara, A., Sazneyoshi, M., and Yamauchi, K. (1994). Changes in serum concentrations of immunoglobulin M $(\operatorname{IgM})$, cortisol and thyroxine $\left(\mathrm{T}_{4}\right)$ during smotification in the masu salmon, Oncorhynchus masou. Fish. Sci. 60, 241-242.

Narnaware, Y. K., Baker, B. I., and Tomlinson, M. G. (1994). The effects of various stresses, corticosteroids and adrengeric agents on phagocytosis in the rainbow trout Oncorhynchus mykiss. Fish Physiol. Biochem. 13, 31-40.

Narnaware, Y. K., and Baker, B. I. (1996). Evidence that cortisol may protect against the immediate effects of stress on circulating leukocytes in the trout. Gen. Comp. Endocrinol. 103, 359-366.

Narnaware, Y. K., Kelley, S. P., and Woo, N. Y. S. (1997). Effect of injected growth hormone on phagocytosis in silver sea bream (Sparus sarba) adapted to hyper- and hypo-osmotic salinities. Fish Shellfish Immunol. 7, 515-517.

Pickering, A. D. (1984). Cortisol-induced lymphocytopenia in brown trout, Salmo trutta L. Gen. Comp. Endocrinol. 53, 252-259.

Pickering, A. D., and Duston, J. (1983). Administration of cortisol to brown trout, Salmo trutta L., and susceptibility to saprolegnia infection and furunculosis. J. Fish Biol. 23, 163-175.

Pottinger, T. G. (1990). The effect of stress and exogenous cortisol on receptor-like binding of cortisol in the liver of rainbow trout, Oncorhynchus mykiss. Gen. Comp. Endocrinol. 78, 194-203.

Pottinger, T. G., Balm, P. H. M., and Pickering, A. D. (1995). Sexual maturity modifies the responsiveness of the pituitary-interrenal axis to stress in male rainbow trout. Gen. Comp. Endocrinol. 98, 311-320.

Roth, J. A., Kaeberle, M. L., Appell, L. H., and Nachreiner, R. F. (1983). Association of increased estradiol and progesterone blood values with altered bovine polymorphonuclear leukocyte function. Am. J. Vet. Res. 44, 247-253.

Roth, J. A., Kaeberle, M. L., and Hsu, W. H. (1982). Effect of estradiol and progesterone on lymphocyte and neutrophil functions in steers. Infect. Immunol. 35, 997-1002.

Sapolsky, R. M., Romero, L. M., and Munck, A. U. (2000). How do glucocorticoids influence stress responses? Integrating permissive, suppressive, stimulatory, and preparative actions. Endocr. Rev. 21, 55-89.

Schuurs, A. H., and Verheul, H. A. (1990). Effects of gender and sex steroids on the immune response. J. Steroid Biochem. 35, 157-172.

Slater, C. H., and Schreck, C. B. (1993). Testosterone alters the immune response of chinook salmon, Oncorhynchus tshawytscha. Gen. Comp. Endocrinol. 89, 291-298.

Slater, C. H., and Schreck, C. B. (1997). Physiological levels of testosterone kill salmonid leukocytes in vitro. Gen. Comp. Endocrinol. 106, 113-119.

Stave, J. W., and Robertson, B. S. (1985). Cortisol suppresses the chemiluminescent response of striped bass phagocytes. Dev. Comp. Immunol. 9, 77-84.

Steel, R. G. D., and Torrie, J. Y. H. (1980). "Principles and Procedures of Statistics." McGraw-Hill, New York.

Strange, R. J., Schreck, C. B., and Golden, J. T. (1977). Cortisol stress response to handling and temperature in salmonids. Trans. Am. Fish. Soc. 106, 213-218.

Sumpter, J. P., Carragher, J., Pottinger, T. G., and Pickering, A. D. (1987). The interaction of stress and reproduction in trout. In "Reproductive Physiology of Fish" (D. R. Idler, L. W. Crim, and J. M. Walsh, Eds.), pp. 299-302. Memorial Univ. Press, St John's, Newfoundland, Canada.

Sun, L. T., Chen, G. R., and Chang, C. F. (1994). Characteristics of blood parameters and gill $\mathrm{Na}^{+}-\mathrm{K}^{+}$-ATPase in chilled comatose tilapia cultured in various salinities. Comp. Biochem. Physiol. 107A, 641-646.

Wang, R., and Belosevic, M. (1995). The in vitro effects of estradiol and cortisol on the function of a long-term goldfish macrophage cell line. Dev. Comp. Immunol. 19, 327-336.

Weyts, F. A. A., Flik, G., and Verburg-van Kemenade, B. M. L. (1998). Cortisol inhibits apoptosis in carp neutrophilic granulocytes. Dev. Comp. Immunol. 22, 563-572.

Weyts, F. A. A., Verburg-van Kemenade, B. M. L., and Flik, G. (1998). Characterization of glucocorticoid receptors in peripheral blood leukocytes of carp, Cyprinus carpio L. Gen. Comp. Endocrinol. 111, 1-8.

Yada, T. Y., Nagae, M., Moriyama, S., and Azuma, T. (1999). Effects of prolactin and growth hormone on plasma immunoglobulin $\mathrm{M}$ levels of hypophysectomized rainbow trout, Oncorhynchus mykiss. Gen. Comp. Endocrinol. 15, 46-52. 